Preliminary communication

\title{
HIGH-PERFORMANCE LIQUID CHROMATOGRAPHIC (HPLC) ANALYSIS OF A CROSSBRED BROWN RICE VARIETY (UKMRC-9) SHOWS HIGH GABA CONTENT
}

\author{
E.E. SAGE ${ }^{\mathrm{a}}$, Y.X. CHANG ${ }^{\mathrm{b}}$, R. WICKNESWARI ${ }^{\mathrm{c}}$ and M.M. MACKEEN ${ }^{\mathrm{a}, \mathrm{d} *}$

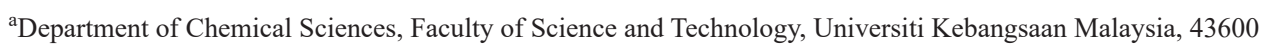 \\ Bangi, Selangor. Malaysia \\ ${ }^{\text {b} P r o g r a m A s a s i P i n t a r, ~ P u s a t ~ P e r m a t a ~ P i n t a r ~ N e g a r a, ~ U n i v e r s i t i ~ K e b a n g s a a n ~ M a l a y s i a, ~} 43600$ Bangi, Selangor. \\ Malaysia \\ ${ }^{\mathrm{c}}$ Department of Earth Sciences and Environment, Faculty of Science and Technology, Universiti Kebangsaan \\ Malaysia, 43600 Bangi, Selangor. Malaysia \\ ${ }^{\mathrm{d}}$ Institute of Systems Biology (INBIOSIS), Universiti Kebangsaan Malaysia, 43600 Bangi, Selangor. Malaysia
}

(Received: 12 March 2019; accepted: 27 March 2020)

The neurotransmitter $\gamma$-aminobutyric acid (GABA) is a functional food ingredient of growing importance in the preparation of GABA-enriched germinated brown rice (GBR). Quantification of GABA levels during germination in a locally developed high yielding red rice variety (UKMRC-9) was carried out via high-performance liquid chromatography (HPLC) analysis using pre-column chemical derivatisation with 2-hydroxynaphthaldehyde (HN) using a UV detection system. Factors that influence rice germination such as soaking time and temperature were also studied. The results of this study showed that the UKMRC-9 rice variety soaked in water for 6 hours at $35^{\circ} \mathrm{C}$ yielded the highest value for both germination percentage $(95.4 \pm 1.2 \%)$ and GABA content $\left(411 \mu^{g^{-1}}\right)$. This suggests that long soaking times of 1-4 days can be substituted by short soaking times to produce high GABA levels in germinated brown rice.

Keywords: germinated brown rice (GBR), $\gamma$-aminobutyric acid (GABA), short soaking time, HPLC-UV, 2-hydroxy-1-naphthaldehyde (HN)

GABA is a non-protein amino acid that can be naturally found in the brain (RoBERTs \& FRANKeL, 1950) and other non-neuronal tissues such as ovarian tissue (Del Rio \& CABALLERO, 1980) in mammals. It can also be found in plants (RooHINEJAD et al., 2009) and even in bacteria (FrANCIOSI et al., 2015). GABA can be produced via biotransformation by treating a glutamic acid decarboxylase (GAD)-overproducing strain of $E$. coli with large amounts of L-glutamic acid, which is the precursor to GABA (PLOKHOv et al., 2000). Yeasts such as Saccharomyces cerevisiae can also be genetically engineered to enhance GAD protein expression to produce endogenous GABA (KANAI et al., 1996). In mammals, GABA acts as a major inhibitory neurotransmitter on GABA receptors (ionotropic/metabotropic) (ОВATA, 2013). GABA has been shown to increase insulin secretion and reduced depressive-like behaviour in mouse models (Patterson et al, 2019). Human GABA intake is proposed to stimulate both motor learning and subconscious motor control (Boy et al., 2010; STAGG et al.,

* To whom correspondence should be addressed.

E-mail: mukram.mackeen@ukm.edu.my 
2011). Naturally occurring GABA is usually derived from glutamate in the cytosol via glutamate decarboxylase, which is regulated by both $\mathrm{pH}$ and $\mathrm{Ca}^{2+} /$ calmodulin (CARroll et al., 1994; SNEDDEN et al., 1995; Bown et al., 2006). However, there are certain conditions that cause GABA to be upregulated in plants such as high light and salinity (decreases water potential and stomatal conductance, while preserving the photosynthetic capability of plants) (WoOdrow et al., 2017).

Germinated brown rice (GBR) is a value-added rice product of growing importance as a functional food especially in countries with rice as their staple food. This is significant in both less economically developed countries that tend to have a high incidence of malnutrition and economically developed countries with lifestyle-related diseases such as type 2 diabetes. The levels of micronutrients such as GABA are significantly elevated during the process of germination via activation of hydrolytic enzymes (SE et al., 2015; ZHAO et al., 2020). GBR can be produced by soaking brown rice grains in water within a certain temperature range ( 35 ${ }^{\circ} \mathrm{C}$ to $40{ }^{\circ} \mathrm{C}$ ) to promote germination and GABA accumulation. A study conducted on six varieties of Thai rice showed that water soaking enriched GABA content in the germ of all rice varieties (BHUIYAN et al., 2011). However, GABA accumulation differed among rice varieties and was influenced by soaking time.

This study aims to determine the optimal conditions to achieve both the highest percentage of germination and GABA content in a crossbred variety of red rice, UKMRC-9, that was developed by University Kebangsaan Malaysia (UKM) and the Malaysian Agricultural Research Institute (MARDI). UKMRC-9 or G33 was derived from advanced backcrosses between a wild rice accession, Oryza rufipogon Griff. IRGC105491 and a Malaysian high-yielding rice cultivar, Oryza sativa L. subsp. indica cv. MR219 (SABU et al., 2006). Experimental field trials and physicochemical analyses have confirmed the superiority of this red rice variety in yield potential and resistance against blast disease and antioxidant properties (BHUIYAN et al., 2011; FASAHAT et al., 2012). UKMRC-9 was also reported to have low glycaemic and insulinogenic properties in two separate studies (FASAHAT et al., 2012; SE et al., 2016).

\section{Materials and methods}

Gamma-aminobutyric acid (GABA) and 2-hydroxynaphthaldehyde (HN) were purchased from Sigma Aldrich.

\subsection{GABA rice germination study}

UKMRC-9 rice samples were collected from the University Kebangsaan Malaysia Plant House Complex. The rice germination procedure was carried out as described previously with slight modification (KOMATSUZAKI et al., 2007). UKMRC-9 grain samples were rinsed before being fully immersed in warm water at $30^{\circ} \mathrm{C}, 35^{\circ} \mathrm{C}, 40^{\circ} \mathrm{C}$, and $45^{\circ} \mathrm{C}$ for $6 \mathrm{~h}, 8 \mathrm{~h}, 10$ $\mathrm{h}$, and $12 \mathrm{~h}$ with water replacement every $2-3.5 \mathrm{~h}$. After that, the rice was rinsed with distilled water, drained and left for 20-26 h. Germination percentage was then determined by counting the total number of sprouted GABA rice grains per total number of rice grains in 10 grams. Then, the samples were oven-dried at $50^{\circ} \mathrm{C}$ for $15 \mathrm{~h}$. After heating, the samples were allowed to cool at room temperature and stored in a $-20^{\circ} \mathrm{C}$ freezer. Finally, the samples were taken out and ground into powder one day before GABA quantification was carried out. 


\subsection{GABA extraction}

The rice GABA extraction was performed as described previously (KomATSUZAKI et al., 2007) with slight modification. In the original method by KoMATSUZAKI and co-workers (2007), $2.5 \mathrm{~g}$ of powdered rice sample was soaked with $25 \mathrm{ml} 70 \%$ ethanol, vortexed for $1 \mathrm{~min}$ at room temperature, and centrifuged for 5 minutes. The extraction method was performed twice to get $50 \mathrm{ml}$ of supernatant, which was then dried and dissolved in $5 \mathrm{ml}$ of lithium citrate elution buffer. This was followed by filtration using a $0.45 \mu \mathrm{m}$ Millipore filter, and it was subjected into the amino acid analyser. In our protocol, a smaller quantity of sample was used $(250 \mathrm{mg}$ ), which was soaked in $0.8 \mathrm{ml}$ of $70 \%$ ethanol and sonicated for 10 minutes. The rice extracts were left standing in the dark at room temperature for one hour. After one hour, the rice samples/extracts were centrifuged at $13600 \times g$ for 1 minute at room temperature. Finally, triplicate samples of the supernatant were concentrated to a final volume of $0.5 \mathrm{ml}$ using a rotary evaporator. The supernatants were collected and kept in a $-20{ }^{\circ} \mathrm{C}$ freezer until further analysis.

\subsection{HN labelling of $G A B A$}

HN labelling of GABA was performed as described previously (KHUHAWAR \& RAJPER, 2003) with slight modification. In the original method, $1 \mathrm{ml}$ of sample was mixed with $0.6 \mathrm{ml}$ Borax buffer $\mathrm{pH} 8$ and $1 \mathrm{ml}$ of $0.3 \% \mathrm{HN}$ in methanol. In our protocol, $0.25 \mathrm{ml}$ of sample was mixed with $0.15 \mathrm{ml}$ Borax buffer $\mathrm{pH} 8$ and $0.25 \mathrm{ml} 0.3 \% \mathrm{HN}$ in methanol. The mixture was incubated in a water bath at $80{ }^{\circ} \mathrm{C}$ for $10 \mathrm{~min}$. After that, the final volume was adjusted to $1 \mathrm{ml}$ using methanol. Finally, the solution was filtered using a $0.45 \mu \mathrm{m}$ filter for subsequent HPLC-UV analysis. The experiment was carried out in the dark to minimise HN degradation. Samples were immediately analysed after derivatisation.

\subsection{Preparation and validation of GABA standard calibration curve}

A triplicate of GABA standard solution $\left(2 \mathrm{mg} \mathrm{ml}^{-1}\right)$ was derivatised using a previously reported method (KHUHAWAR \& RAJPER, 2003). Then, aliquots of the reaction mixture (1 ml) were filtered using a $0.45 \mu \mathrm{m}$ PTFE membrane filter for HPLC-UV analysis. After filtration, two-fold serial dilutions were carried out to prepare concentrations ranging from 1.8 to 890.0 $\mu \mathrm{g} \mathrm{ml}^{-1}$ for the calibration curve. LOD and LOQ values were determined using the equations based on the method reported by ICH (ICH GuIDELINE, 2005) where LOD $=(3.3 \times \delta) / \mathrm{S}$, and $\mathrm{LOQ}=(10 \times \delta) / \mathrm{S}$, where $\delta$ is the standard deviation of the Y-intercept and $\mathrm{S}$ is the slope of the linear regression equations (peak height vs. concentration). Precision and recovery data were also determined using the same reference, where for precision, $6 \mathrm{GABA}$ standard aliquots at $0.5 \mathrm{mg} \mathrm{ml}^{-1}$ were labelled and injected on the same day (intra-day precision) and other sets of the derivatised standard were injected the day after. The recovery data was obtained by spiking non-germinated UKMRC9 extract with $0.25 \mathrm{mg}$ of GABA prior to HN derivatisation. For the degradation test, $6 \mathrm{GABA}$ standard aliquots at $0.5 \mathrm{mg} \mathrm{ml}^{-1}$ were labelled and injected into the HPLC-UV system. The sample set was kept at $-20^{\circ} \mathrm{C}$ for $24 \mathrm{~h}$ and injected into the HPLC-UV system using the same method.

\subsection{HPLC analysis of HN labelled samples}

GABA standards and samples labelled with $\mathrm{HN}$ were analysed in triplicate using an Agilent 1100 HPLC instrument. The column used was a reverse phase C18 column $(2.1 \mathrm{~mm}$ ID $\times 150$ $\mathrm{mm}, 3.5 \mu \mathrm{m}$, Waters Atlantis) used at $25{ }^{\circ} \mathrm{C}$. An isocratic solvent system of $55 \%$ acetonitrile 
with $45 \%$ of $0.1 \%$ acetic acid was used as the mobile phase with the flow rate of $0.2 \mathrm{ml}$ $\min ^{-1}$. The derivatised samples and standards $\left(1.8-890 \mu \mathrm{g} \mathrm{ml}^{-1}\right)$ were filtered using $0.45 \mu \mathrm{m}$ PTFE membrane filters and injected at the volume of $0.5 \mu 1$. The UV detection was carried out at $254 \mathrm{~nm}$.

\section{Results and discussion}

Pre-column derivatisation with 2-hydroxynapthaldehyde (HN) followed by HPLC-UV analysis $(254 \mathrm{~nm})$ was successfully used to determine GABA content in germinated rice extract from the UKMRC-9 variety. In the Materials and Methods section, it was mentioned that the derivatised samples were analysed as soon as possible, because although it has been shown that the GABA-HN peak is highly stable (no change in UV absorbance was observed up to 48 hours) (HAYAT et al., 2014), our degradation study suggests otherwise. A pairedsamples $t$-test was conducted to compare the peak height of freshly prepared GABA-HN (Day1, D1) and after $24 \mathrm{~h}$ of storage in the dark at $-20{ }^{\circ} \mathrm{C}$ (Day 2, D2) samples with the assumption the response data is normally distributed. There is a significant difference in the peak height of GABA-HN on D1 $(\mathrm{M}=44109.7, \mathrm{SD}=3724.3)$ and $\mathrm{D} 2(\mathrm{M}=36319.5, \mathrm{SD}=9449.6)$ with the conditions $\mathrm{t}(5)=-2.64, \mathrm{p}=0.02(<0.05)$. Therefore, freshly prepared derivatised samples were used for our HPLC-UV analyses.
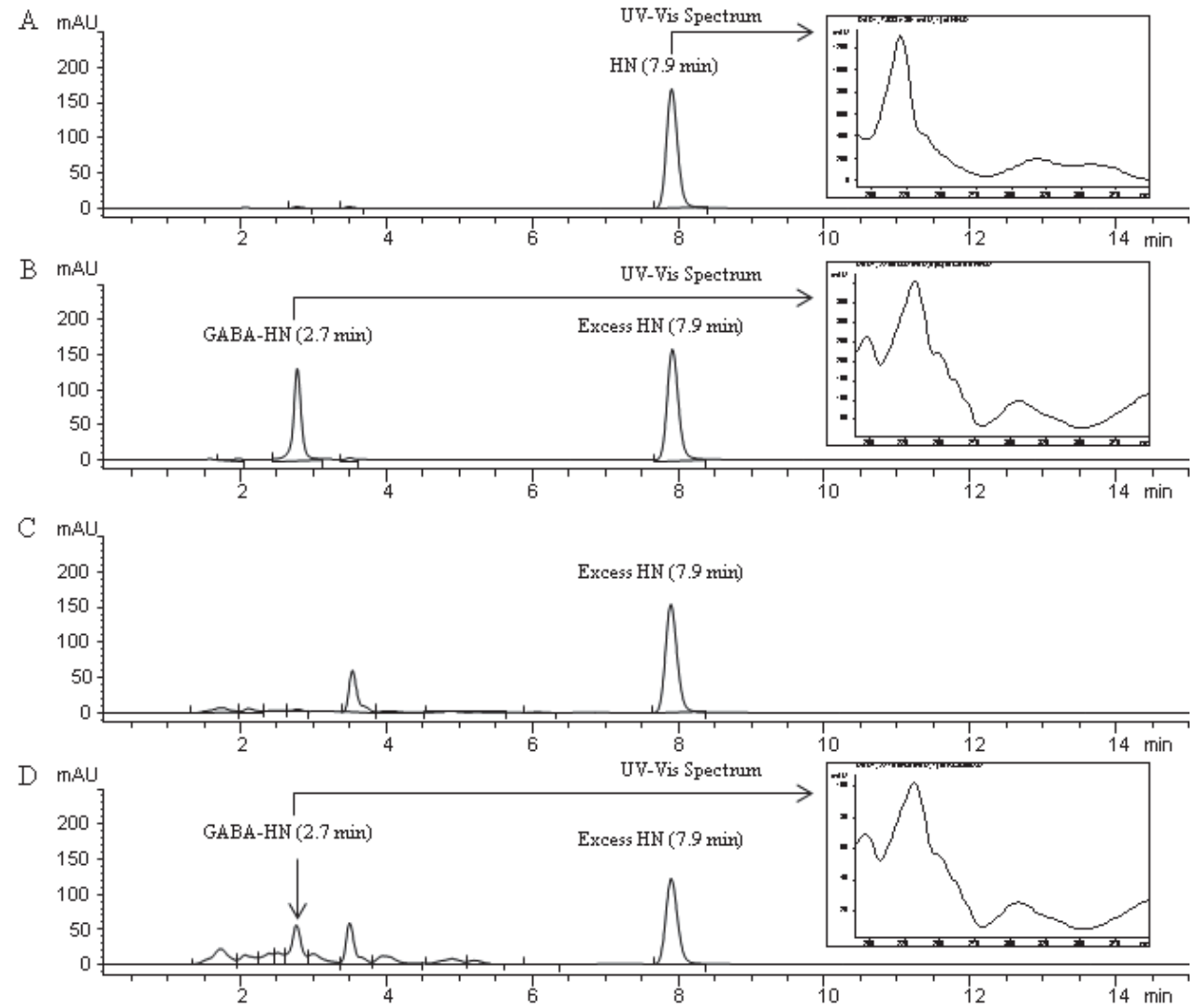

Fig. 1. UV-derived chromatograms of $\mathrm{HN}$ derivatising reagent in $\mathrm{MeOH}(\mathrm{A})$, derivatised GABA standard with excess $\mathrm{HN}$ labelling reagent (B), UKMRC-9 treated at $45^{\circ} \mathrm{C}$ for $6 \mathrm{~h}(\mathrm{C})$, and treated at $35^{\circ} \mathrm{C}$ for $6 \mathrm{~h}$ (D) 
The GABA-HN labelled peak in the GBR samples showed both identical retention times ( $\mathrm{R}_{\mathrm{t}} 2.7 \mathrm{~min}$ ) and UV spectra to the GABA-HN standard peak (Fig. 1). The calibration curve of derivatised GABA-HN standard within the range of $0.9-179.5 \mathrm{ng}$ was represented by the linear equation $\mathrm{y}=1.86 \mathrm{x}+3.13$ with the $\mathrm{R}^{2}$ value of 0.999 (Fig. 2). The lowest limit of detection (LOD) was at $3.97 \mathrm{ng}$, while the lowest limit of quantification (LOQ) was at 13.2 ng for the GABA-HN derivative peak. Precision analyses showed that both the measured intra-day and inter-day repeatability reported as relative standard deviation percentage (RSD) values were $7.7 \%(\mathrm{n}=6)$ and $8.6 \%(\mathrm{n}=10)$, respectively. The recovery level of GABA from the spiked extracts was high $(96.0 \pm 0.3 \%, \mathrm{n}=4)$.

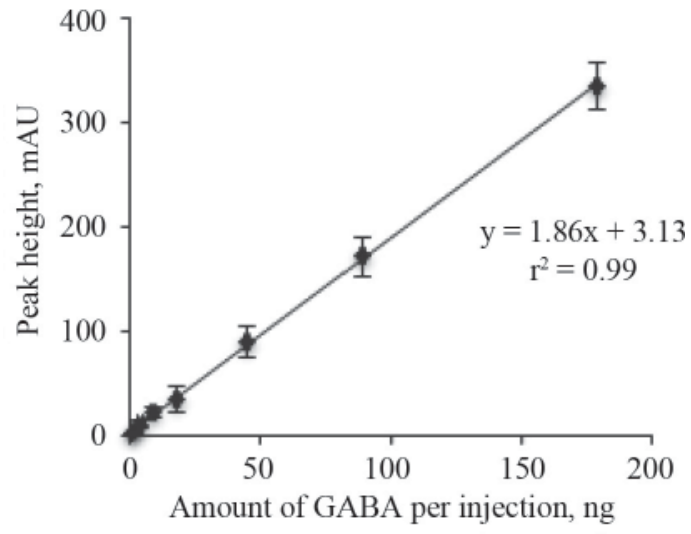

Fig. 2. GABA calibration curve based on peak height using HPLC-UV (254 nm)

The mean scores of germinations percentage for $30^{\circ} \mathrm{C}, 35^{\circ} \mathrm{C}$, and $40^{\circ} \mathrm{C}$ are $83.1 \pm 7.3 \%$, $95.4 \pm 1.2 \%$, and $80.7 \pm 10.3 \%$, respectively ( $6 \mathrm{~h}$ soaking time) (Fig. 3 ). However, there was no observable sprouting of UKMRC-9 when treated at $45{ }^{\circ} \mathrm{C}$ and it was thus considered unsuitable for germination. The treatment time chosen for the determination of germination percentage was the minimum time required for the UKMRC-9 rice grains to sprout (6 hours). UKMRC-9 rice sample treated at $35^{\circ} \mathrm{C}$ contained the highest amount of GABA $\left(411 \mu \mathrm{g} \mathrm{g}^{-1}\right)$, while the opposite was observed for the rice sample that was treated at $45^{\circ} \mathrm{C}\left(4.5 \mu \mathrm{g} \mathrm{g}^{-1}\right)$ (Fig. 4A). This is probably due to the lack of germination in UKMRC-9 sample treated at 45 ${ }^{\circ} \mathrm{C}$ resulting in a negligible amount of GABA. Apart from temperature, the treatment time factor was also studied in this project. As shown in Figure 4B, UKMRC-9 rice sample treated at $35^{\circ} \mathrm{C}$ (optimum temperature to produce the maximum amount of GABA) showed that the highest amount of GABA was present at the early stage of germination and decreased steadily every $2 \mathrm{~h}$ until it reached equilibrium ( $10 \mathrm{~h}$ and above). This decrease is probably due to the inactivation of glutamate decarboxylase, that is involved in the synthesis of GABA and GABA-degrading proteolytic enzymes (SAIKUSA et al., 1994). Therefore, germination of UKMRC-9 resulted in the accumulation of GABA as observed in a previous study on Malaysian brown rice varieties using multiple soaking (every $12 \mathrm{~h}$ ) for germination at $30{ }^{\circ} \mathrm{C}$ over a long period of 4 days (RoOHINEJAD et al., 2011). MRQ74 was reported as the variety that presented the highest GABA content ( $200 \mu \mathrm{g} \mathrm{g}^{-1}$ for 24 hours; $440 \mu \mathrm{g} \mathrm{g}^{-1}$ for 48 hours; 
$940 \mu \mathrm{g} \mathrm{g}^{-1}$ for $72 \mathrm{~h}$; and $1810 \mu \mathrm{g} \mathrm{g}^{-1}$ for $96 \mathrm{~h}$ ). Additionally, other non-Malaysian brown rice varieties have shown either lower GABA contents for the germination period of 24 hours (KomATSUZAKI et al., 2007) or comparable levels of GABA after a much longer germination period of 72 hours (DING et al, 2016). However, our results showed that a short 6 hour soaking time at $35^{\circ} \mathrm{C}$ of UKMRC-9 presented the highest sprouting percentage $(95.4 \%)$ and GABA level $\left(411 \mu \mathrm{g} \mathrm{g}^{-1}\right)$ with only a single change of water, comparable to the level produced by MRQ74 after 48 hours with 3 water replacements.

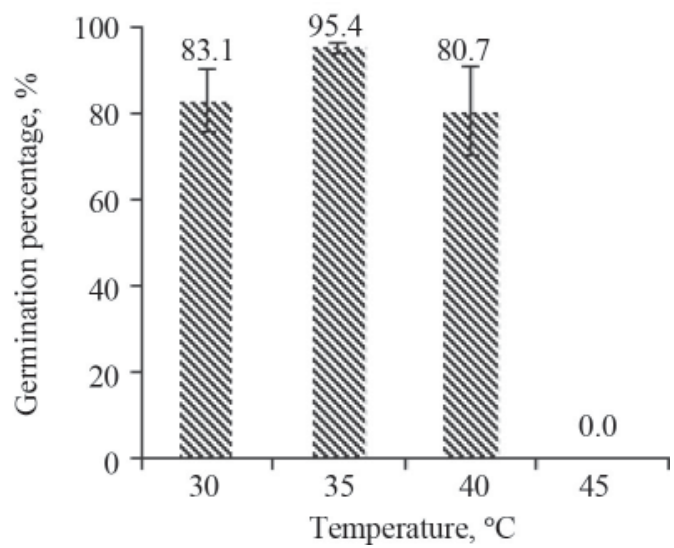

Fig. 3. Germination percentage (\%) of UKMRC9 at different treatment temperatures
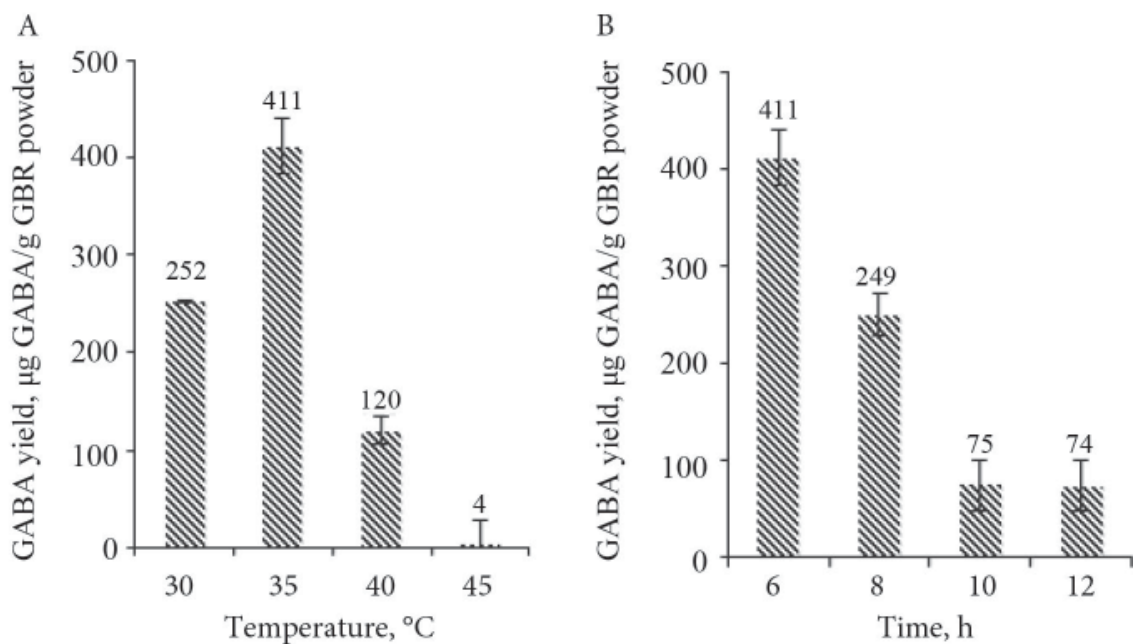

Fig. 4.A) GABA yield ( $\mu \mathrm{g}$ GABA g ${ }^{-1}$ GBR powder) in UKMRC-9 at different temperatures after 6 hours of soaking, and B) GABA yield ( $\mu$ g GABA g ${ }^{-1}$ GBR powder) in UKMRC-9 at different treatment times $\left(35^{\circ} \mathrm{C}\right)$ 


\section{Conclusions}

HPLC analysis of GABA with pre-column HN derivatisation for UV detection was suitable for the evaluation of factors that influence the production of GABA via germination, such as temperature and soaking time. The crossbred red rice variety UKMRC-9 produced the highest level of GABA at $35^{\circ} \mathrm{C}$ (highest sprouting percentage) in a single step of water soaking for 6 hours. Therefore, this represents an attractive alternative to long soaking times to increase GABA content that has been previously reported.

This study was funded by research grants from the Ministry of Higher Education, Malaysia (Grant Code: LRGS/ TD/2011/UPM-UKM/KM/01) and Universiti Kebangsaan Malaysia (Grant Code: ST-2014-003).

\section{References}

Bhuiyan, M., Narimah, M., Rahim, H.A., Abdullah, M. \& Wickneswari, R. (2011): Transgressive variants for red pericarp grain with high yield potential derived from Oryza rufipogon $\times$ Oryza sativa: Field evaluation, screening for blast disease, QTL validation and background marker analysis for agronomic traits. Field Crop Res.,121, 232-239.

Bown, A.W., MacGregor, K.B. \& Shelp, B.J. (2006): Gamma-aminobutyrate: Defense against invertebrate pests? Trends Plant Sci., 11, 424-427.

Boy, F., Evans, C.J., Edden, R.A., Singh, K.D., Husain, M. \& Sumner, P. (2010): Individual differences in subconscious motor control predicted by GABA concentration in SMA. Curr. Biol., 20, 1779-1785.

Carroll, A.D., Fox, G.G., Laurie, S., Phillips, R., Ratcliffe, R.G. \& Stewart, G.R. (1994): Ammonium assimilation and the role of [gamma]-aminobutyric acid in $\mathrm{pH}$ homeostasis in carrot cell suspensions. Plant Physiol., 106, 513-520.

Del Rio, R.M. \& CABallero, A.L. (1980): Presence of $\gamma$-aminobutyric acid in rat ovary. J. Neurochem., 34, 1584 1586.

Ding, J., Yang, T., Feng, H., Dong, M., Slavin, M., ... \& ZhaO, S. (2016): Enhancing contents of $\gamma$-aminobutyric acid (GABA) and other micronutrients in dehulled rice during germination under normoxic and hypoxic conditions. J. Agr. Food Chem., 64(5),1094-1102.

Fasahat, P., Abdullah, A., Muhammad, K., Karupaiah, T.\& Ratnam, W. (2012): Red pericarp advanced breeding lines derived from Oryza rufipogon $\times$ Oryza sativa: Physicochemical properties, total antioxidant activity, phenolic compounds and vitamin E content. Adv. J. Food Sci. Technol., 4, 155-165.

Franciosi, E., Carafa, I., Nardin, T., Schiavon, S., Poznanski, E. ... \& Tuohy, K.M. (2015): Biodiversity and $\gamma$-aminobutyric acid production by lactic acid bacteria isolated from traditional alpine raw cow's milk cheeses. Biomed Res. Int., 2015, 625740.

ICH GuIDELINE (2005): Validation of analytical procedures: Text and methodology Q2 (R1). -in: International Conference On Harmonization, Geneva, Switzerland, pp. 11-12.

Hayat, A., Jahangir, T.M., Khuhawar, M.Y., Alamgir, M., Siddiqui, A.J. \& Musharraf, S.G. (2014): Simultaneous HPLC determination of gamma-aminobutyric acid (GABA) and lysine in selected Pakistani rice varieties by pre-column derivatization with 2-hydroxynaphthaldehyde. J. Cereal Sci., 60(2), 356-360.

Kanai, T., Atomi, H., Umemura, K., Ueno, H., Teranishi, Y., ... \& Tanaka, A. (1996): A novel heterologous gene expression system in Saccharomyces cerevisiae using the isocitrate lyase gene promoter from Candida tropicalis. Appl. Microbiol. Biot., 44, 759-765.

KHUHAWAR, M.Y. \& RAJPER, A.D. (2003): Liquid chromatographic determination of gamma-aminobutyric acid in cerebrospinal fluid using 2-hydroxynaphthaldehyde as derivatizing reagent. J. Chromatogr. B, 788, 413-418.

Komatsuzaki, N., Tsukahara, K., Toyoshima, H., Suzuki, T., Shimizu, N. \& Kimura, T. (2007): Effect of soaking and gaseous treatment on GABA content in germinated brown rice. J. Food Eng., 78, 556-560.

OвAтA, K. (2013): Synaptic inhibition and $\gamma$-aminobutyric acid in the mammalian central nervous system. 89, 139156. 
Patterson, E., Ryan, P.M., Wiley, N., Carafa, I., Sherwin, E., .. \& \& Ross, R.P. (2019): Gamma-aminobutyric acidproducing lactobacilli positively affect metabolism and depressive-like behaviour in a mouse model of metabolic syndrome. Sci. Rep., 9(1), 1-15.

Plokhov, A.Y., Gusyatiner, M., Yampolskaya, T., Kaluzhsky, V., Sukhareva, B. \& Schulga, A. (2000): Preparation of $\gamma$-aminobutyric acid using E. coli cells with high activity of glutamate decarboxylase. Appl. Biochem. Biotech., 88, 257-265.

Roberts, E. \& Frankel, S. (1950): $\gamma$-Aminobutyric acid in brain: its formation from glutamic acid. J. Biol. Chem., $187,55-63$

Roohinejad, S., Mirhosseini, H., Saari, N., Mustafa, S., Alias, I., .. \& Manap, M.Y. (2009): Evaluation of GABA, crude protein and amino acid composition from different varieties of Malaysian's brown rice. Aust. J. Crop Sci., 3, 184.

Roohinejad, S., Omidizadeh, A., Mirhosseini, H., Saari, N., Mustafa, S., .. \& Abd Manap, M.Y. (2011): Effect of pre-germination time on amino acid profile and gamma aminobutyric acid (GABA) contents in different varieties of Malaysian brown rice. Int. J. Food Prop., 14, 1386-1399.

Sabu, K.K., Abdullah, M.Z., Lim, L.S. \& Ratnam, W. (2006): Development and evaluation of advanced backcross families of rice for agronomically important traits. Commun. Biometry Crop Sci., 1, 111-123.

SAIKUSA, T., Horino, T. \& MoRI, Y. (1994): Accumulation of $\gamma$-aminobutyric acid (GABA) in the rice germ during water soaking. Biosci. Biotech. Bioch., 58, 2291-2292.

Se, C.H., Chuah, K.-A., Mishra, A., Ratnam, W. \& Karupaiah, T. (2016): Evaluating crossbred red rice variants for postprandial glucometabolic responses: A comparison with commercial varieties. Nutrients, 8, 308. (16 pages)

Se, C.H., Khor, B.H. \& Karupaiah, T. (2015): Prospects in development of quality rice for human nutrition. Malays. Appl. Biol., 44, 1-31.

Snedden, W.A., Arazi, T., Fromm, H. \& Shelp, B.J. (1995): Calcium/calmodulin activation of soybean glutamate decarboxylase. Plant Physiol., 108, 543-549.

Stagg, C.J., Bachtiar, V. \& Johansen-Berg, H. (2011): The role of GABA in human motor learning. Curr. Biol., $21,480-484$.

Woodrow, P., Ciarmiello, L.F., Annunziata, M.G., Pacifico, S., Iannuzzi, F., ... \& Carillo, P. (2017): Durum wheat seedling responses to simultaneous high light and salinity involve a fine reconfiguration of amino acids and carbohydrate metabolism. Physiol. Plant., 159, 290-312.

Zhao, M., Lin, Y. \& CHen, H. (2020): Improving nutritional quality of rice for human health. Theor. Appl. Genet., 8, $1-17$. 